\title{
Titanium Research Developments in the United Kingdom
}

\author{
Martin Jackson \\ Department of Materials Science and Engineering, The University of Sheffield, Mappin Street, Sheffield, S1 3JD, UK
}

\begin{abstract}
$\underline{\text { Abstract }}$
The paper presents highlights of the titanium alloy research developments since Ti-2015 (San Diego). The review underlines the strong and collaborative fundamental research conducted at UK universities through strategic government sponsored programmes. The role of advanced characterisation and modelling techniques in order to better understand the effects of deformation, fatigue loading and environment on titanium alloys continues to be world leading. Researchers in the UK are also continuing to develop a range of new alloys, methods of extraction and emerging near net shape processes via casting, powder and wire-fed routes.
\end{abstract}

\section{UK Ti Research Landscape}

Over the last 10 years, the $£ 50$ million Rolls-Royce / Engineering and Physical Sciences Research Council (EPSRC) Strategic Partnership Flagship Programme in Structural Metallic Systems for Gas Turbine Applications has a clear aim: through fundamental research, to provide the foundation for next-generation aero-engines. With respect to Ti research the jointfunded initiative utilises and extends the capabilities of Cambridge, Oxford, Birmingham and Swansea Universities. A unique feature of this Rolls-Royce / EPSRC Programme was the inclusion of a parallel training programme delivered by an EPSRC Centre for Doctoral Training (CDT). Through this Centre, PhD and EngD students research industry-relevant issues and contribute to the development of engine components destined to enter commercial service. Up until 2019, around 100 students have joined the programme with over $60 \%$ of those graduating recruited to Rolls-Royce or the supply chain, many of whom are working on Ti technical challenges.

In 2019, the EPSRC Centre for Doctoral Training in Advanced Metallics Systems (The Univ. of Sheffield and Manchester, partnering with I-Form the SFI Research Centre for Advanced Manufacturing in Dublin, received a further 5 years funding and $>£ 5 \mathrm{M}$ investment from EPSRC and a further $£ 4 \mathrm{M}$ from industry for 70 studentships. Interestingly over the last 10 years, Ti projects have seen the largest growth of any metallic project, training graduates from a range of backgrounds into Ti metallurgists.

Over the last four years, the UK has continued to produce key discoveries at the fundamental level through to new emerging near net shape processing methods. One of the most important EPSRC programmes since Ti-2015 was HexMat (Heterogeneous Mechanics in Hexagonal Alloys across Length and Time Scales). This successful five-year collaborative programme between Imperial College London, Univ. Manchester and Univ. Oxford has provided value insights into the fundamental mechanisms in Ti and its performance in the aerospace sector. The programme has allowed UK experts to develop a range of experimental, characterisation and modelling techniques for Ti. The key Ti industry partners during HexMat were Timet and Rolls-Royce, who are also largely responsible for the majority of Ti alloy research in the UK. 


\subsection{HexMat Case Study 1 - Dwell Fatigue Modelling}

Dwell fatigue has been a long-standing problem in aero-engine Ti components, and particularly for discs. During late stages of take-off and early cruise, the resulting high stress holds give rise to creep in crystallographic regions well-orientated for slip, leading to stress redistribution on to adjacent crystallographic regions badly orientated which cyclically ratchets and leads to basal facet formation and potentially subsequent crack growth. This results in a dwell fatigue debit (often a substantial reduction in cyclic life compared to conventional fatigue). Fundamental property quantification has been carried out at Imperial for alpha and beta phases respectively, in various alloys by integrating micro-pillar testing, quantitative characterisation and crystal plasticity modelling (see Fig. 1). Interestingly, the basal, prismatic and slip systems show markedly differing strain rate sensitivities thereby affecting local creep response and stress redistribution in dwell fatigue [1]. Crystal and dislocation plasticity models utilise the key property data to facilitate microstructural analyses to understand and quantify the local creep and load shedding, the stress build up and the facet nucleation process [2].

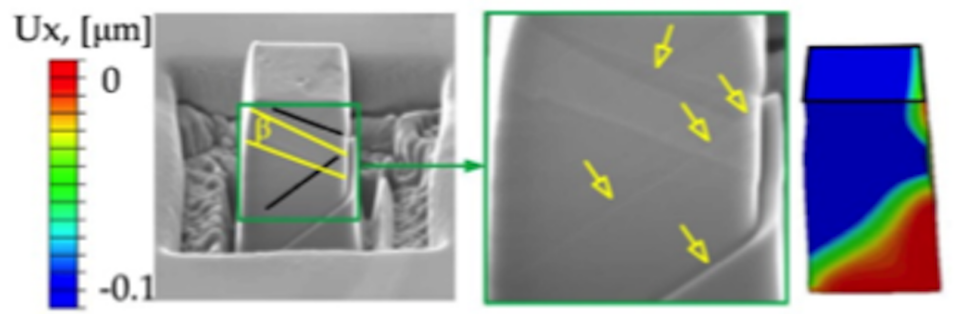

Figure 1: Micro-compression test on alpha-beta pillar and crystal plasticity modelling. Yellow arrows highlight active slip [1]. (Courtesy of Fionn Dunne)

The modelling work permits the investigation of behaviour in virtual microstructures and in representative in-service conditions so that rig spin tests carried out by Rolls-Royce may be interpreted in the context of the full thermomechanical loading of in-service discs. These studies have demonstrated the role of temperature, alpha-beta microstructure, thermal alleviation, and stress state in dwell fatigue [3], and have provided the pathway to dwell-resistant microstructures. Fig. 2 shows an example IMI834 microstructure, together with the results of modelling studies to explain observed dwell failures in disc spin tests versus safe operation for in-service thermomechanical conditions. A crucial over-arching conclusion is that while the chemistry and processing in $\mathrm{Ti}$ alloys give rise to the microstructure, it is the latter which is crucial to controlling dwell debit (and not, for example, Mo content, as has been believed for decades). Optimal dwell resistant microstructures are those which exploit basketweave morphologies, and secondary alpha, ideally with high numbers of alpha variants, to inhibit soft grain region creep and hence stress ratcheting in hard regions.
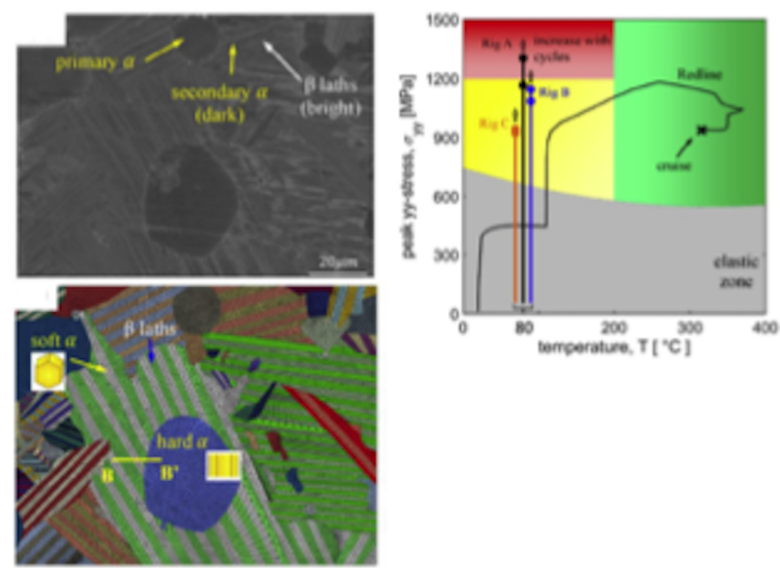

Figure 2: (a) IMI834 alpha-beta microstructure and (b) representative crystal plasticity modelling, and (c) hard grain stresses and thermomechanical operational map of dwell fatigue sensitivity for spin tests and in-service conditions [3]. (Courtesy of Fionn Dunne)

The dwell fatigue work within the EPSRC-funded programme grant HexMat [4] has had international impact with new high-level TRL collaborations with Pratt \& Whitney, Honeywell, GE, Rolls-Royce, IHI, AFRL and the FAA. Ref 4 also has a weblink to the key journal papers from this programme. 


\subsection{HexMat Case Study 2 - Strain localisation in macrozones}

In tandem with the activities at Imperial College London, the Univ. Manchester have refined their high resolution digital image correlation (HRDIC) technique in order to determine the effect of hard oriented macrozones on the local slip activity [5]. In combination with grain orientation (EBSD) and strain (HRDIC), large area high resolution strain maps showed there is very diffuse and homogeneous slip in the hard macrozone region compared to more planar and localised slip in the neighbouring (softer) region occurring by prismatic or basal slip (Fig. 3). Relative Displacement Ratio (RDR) analysis was utilised in combination with traditional slip trace analysis to identify the active slip mode in each grain which was validated by TEM analysis.

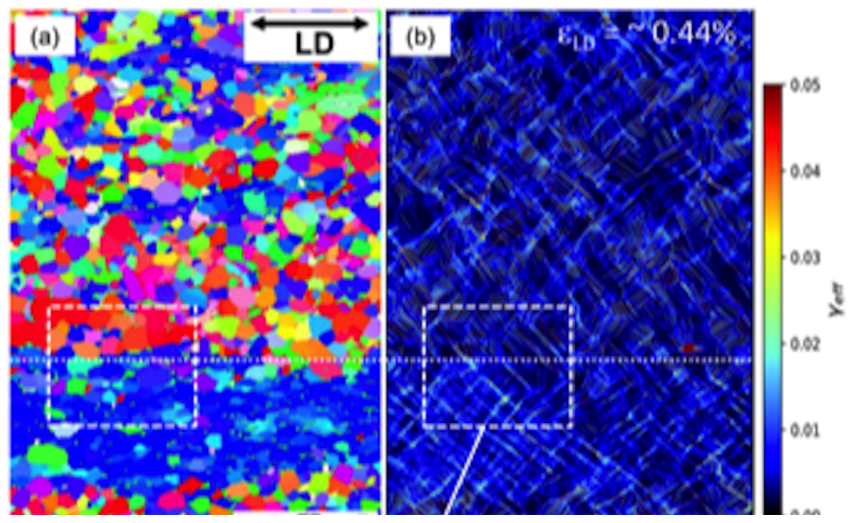

Figure 3: Strain localisation in Ti-6Al-4V UD rolled plate with hard oriented macrozones when loaded along RD. (a) IPF TD map, (b) effective shear strain map at $\sim 0.5 \%$ applied strain across an area of $0.36 \times 1.08 \mathrm{~mm}^{2}$ with (c) magnified view to highlight difference in slip either side of the macrozone boundary and (d) TEM micrographs collected under various electron beam directions confirming slip in a single grain lifted out from the hard oriented macrozone region. (Courtesy of João Quinta de Fonseca)

\subsection{Small punch fatigue testing}

Following the successful application of small punch test techniques for the assessment of static and creep properties of various aero-engine materials [6], recent attention has transferred to the development of small punch fatigue capability. In this regard, the alloy Ti-6Al-4V in various conventional (cast and forged) and additive (electron beam melt) forms has been employed to validate the technique $[7,8]$ producing representative S-N curves in agreement with traditional uniaxial approaches (evidenced through empirical data and FE modelling, Fig. 4 top). Classical fatigue mechanisms are replicated in small punch samples, including cyclic plasticity ("cold creep") and striated fatigue crack growth (Fig. 4). The ability to monitor constitutive behaviour (load-displacement loops akin to stress-strain data, Fig. 4) and the sensitivity of the test to subtle microstructure variations, offer an improved representation of the fatigue properties of additive materials. Small punch discs can usually be extracted from the final built component, however complex or restricted in section size. This offers direct sampling of the component, rather than the reliance on separately built test specimens where the combination of macroscopic sample geometry and additive process parameters induce a non-representative microstructure. 


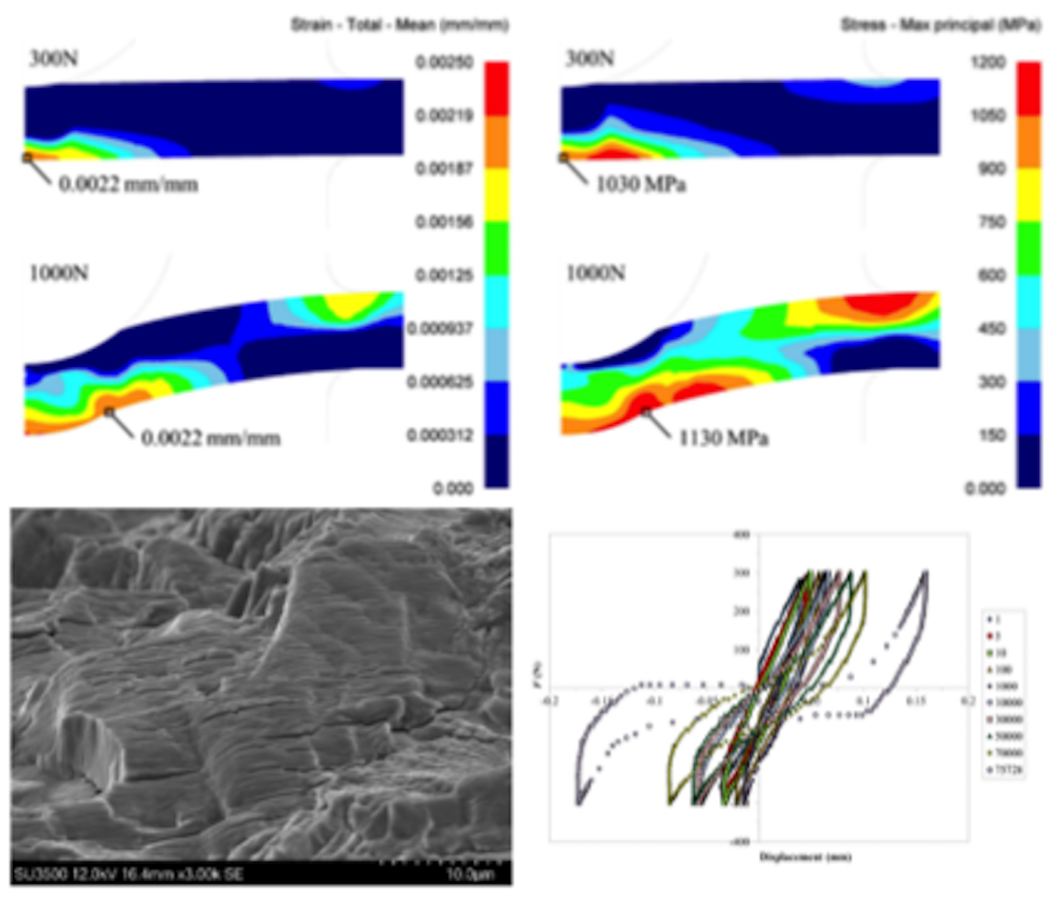

Figure 4: (Top) Prediction of mean strain and maximum principal stress distributions across a SPF specimen after 100 fatigue cycles of different applied load. (Bottom Left) Evidence of striations from a SPF test on Ti-6Al-4V, $20^{\circ} \mathrm{C}, \mathrm{R}=0.1$. (Bottom right) Loaddisplacement hysteresis loops for a SPF test on a Ti-6Al-4V, $20^{\circ} \mathrm{C}, \mathrm{R}=-1$ [7]. (Courtesy of Rob Lancaster and Martin Bache)

\subsection{Metastable Beta Alloy Development}

Since the last World Titanium conference in 2015, research at the Univ. Cambridge has continued to focus on the fundamental aspects of metastable beta Ti alloys and, in particular, on their associated phase transformations, both reconstructive and diffusionless.

Work investigating the effect of low temperature heat treatments on the microstructure of Ti-15Mo (wt.\%) has discovered the formation of a previously unreported B2 phase, see fig.5[9]. The formation mechanism of this phase remains under debate although as the phase was only observed to form in thin foils, both hydrogen and a reduction in constraint have been postulated.
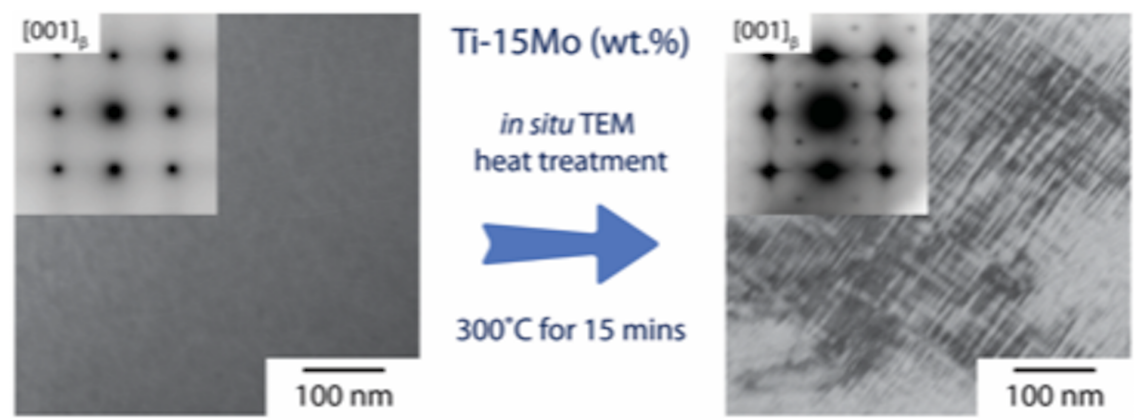

Figure 5: Ti-15Mo (wt.\%) prior to and following in situ heat treatment at $300^{\circ} \mathrm{C}$ in the TEM: (Left), SADP down the $[001]_{\beta}$ prior to heating with corresponding BF image of the microstructure. (Right) SADP down the $[001]_{\beta}$ following 15 min at $300{ }^{\circ} \mathrm{C}$ and d) corresponding BF image of the microstructure [9] (Courtesy of Nicholas Jones).

The influence of $\mathrm{Zr}$ on the superelastic properties and the stability of the omega phase in Ti-Nb alloys have been investigated using a combination of synchrotron X-ray radiation, advanced electron microscopy and atom probe tomography (Fig. 6). $\mathrm{Zr}$ was widely believed to be a strong omega suppressant commonly added to commercial alloys to mitigate the impact of this phase. However, the recent work from Univ. Cambridge has shown that whilst this might be true for the athermal form, Zr has very 
little preventative effect on the formation of isothermal omega [10]. In situstudies investigating the transformational behaviour of $\mathrm{Ti}-\mathrm{Nb}-\mathrm{Zr}$ alloys in response to variations in temperature and applied loads have also revealed some very interesting findings, which require the mechanistic understanding of these transformations to be revisited.

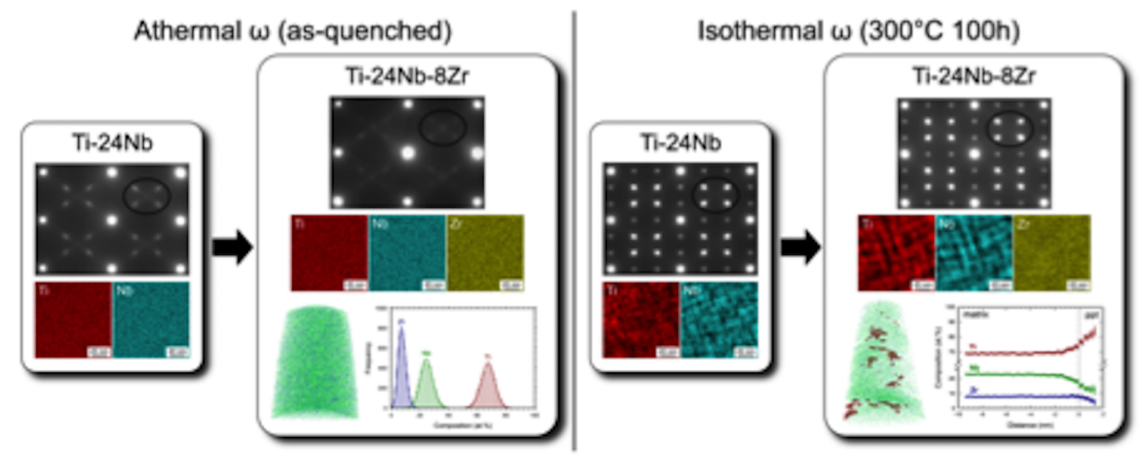

Figure 6: Graphical illustration of the role of $\mathrm{Zr}$ on $\omega$ phase formation in $\mathrm{Ti}-\mathrm{Nb}$ alloys using $\mathrm{X}$-ray diffraction, transmission electron microscopy and atom probe tomography [10] (Courtesy of Nicholas Jones)

\section{Alternative extraction processes}

A new, novel method of $\mathrm{Ti}$ production via calciothermic reduction of $\mathrm{TiO}_{2}$, developed at the Univ. Bradford. The Bradford Process is observed to be faster, cheaper and more environmentally friendly that competing methods - most notably the industry standard Kroll process (Fig. 7). After proving the initial proof of concept the Univ. Bradford has developed the process to the point it is ready for technical demonstrations $(<5 \mathrm{~kg} \mathrm{CP}$ Ti production) having built a bespoke furnace and secured all appropriate IP relating to the process.
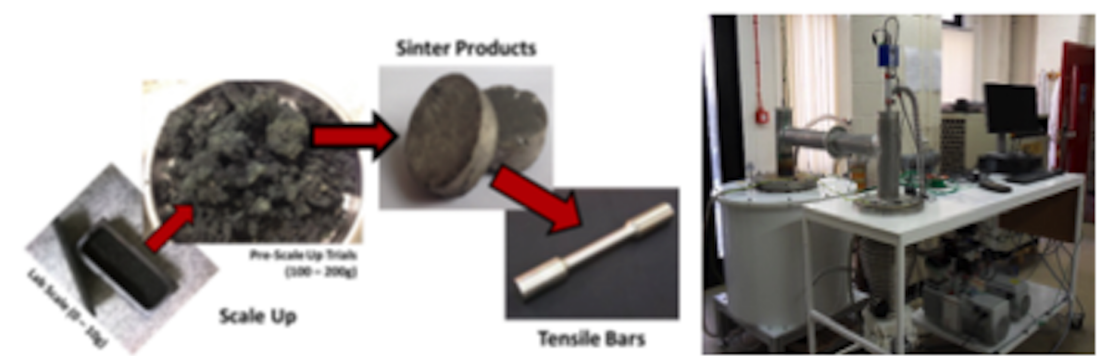

Figure 7: (Left) Photograph of Ti product derived from "The Bradford Process"; (Right) Bespoke, small scale calciothermic reduction cell at the Univ. Bradford (Courtesy of Russell Hodgetts).

Metalysis are continuing to scale up their operation now the process has been successfully demonstrated on the small sale. Generation 4 is the first facility to take Metalysis' solid-state, modular, electrochemical process to industrial scale (Fig. 8) and can produce tens-to-hundreds of tonnes per annum of high value, niche and master alloys. In 2017, Metalysis expanded into additional facilities at their Materials Discovery Centre, now sandwiched between state-of-the-art Rolls-Royce and McLaren factories on the Advanced Manufacturing Park in Rotherham, South Yorkshire.
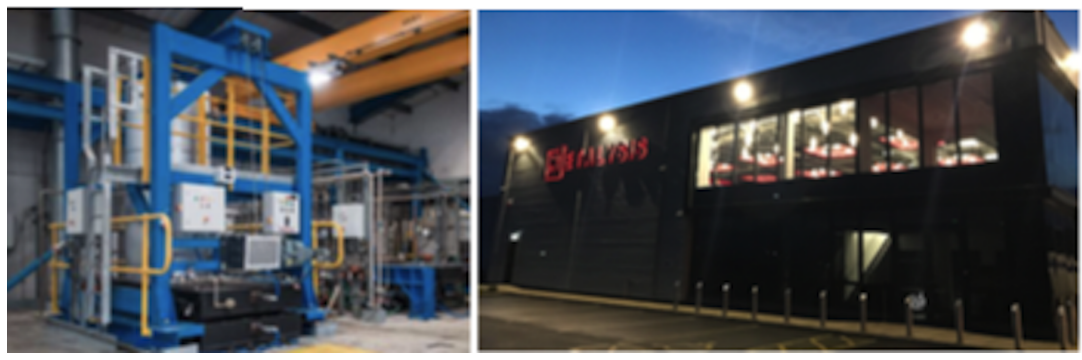
Figure 8: Photograph of (Left) Metalysis' Generation4 industrial plant and (Right) Metalysis' Materials Discovery Centre on Advanced Manufacturing Park, Rotherham, South Yorkshire. (Courtesy of Ian Mellor)

\title{
4. Emerging near net shaping technologies
}

\author{
4.1 Wire Arc Additive Manufacturing (WAAM)
}

A team comprising of Thales Alenia Space, Cranfield Univ. and Glenalmond Technologies have successfully produced a first full-scale prototype of a Ti pressure vessel to be used in future manned missions for space exploration. The vessel in Fig. 9 is made from Ti-6Al-4V and is approximately $1 \mathrm{~m}$ in height and $8.5 \mathrm{~kg}$ in mass. It has been deposited using the Wire + Arc Additive Manufacturing (WAAM) process [11]. The Cranfield Univ. developed WAAM process provides an exciting opportunity to go straight from a digital drawing to final structure. WAAM has integrated two individual pieces into a single part; eliminating the need for long-lead-time forgings; and substantially reduced the amount of waste material removed by machining. It is estimated that more than $200 \mathrm{~kg}$ of Ti-6Al-4V have been saved compared to a conventional forging machining route.
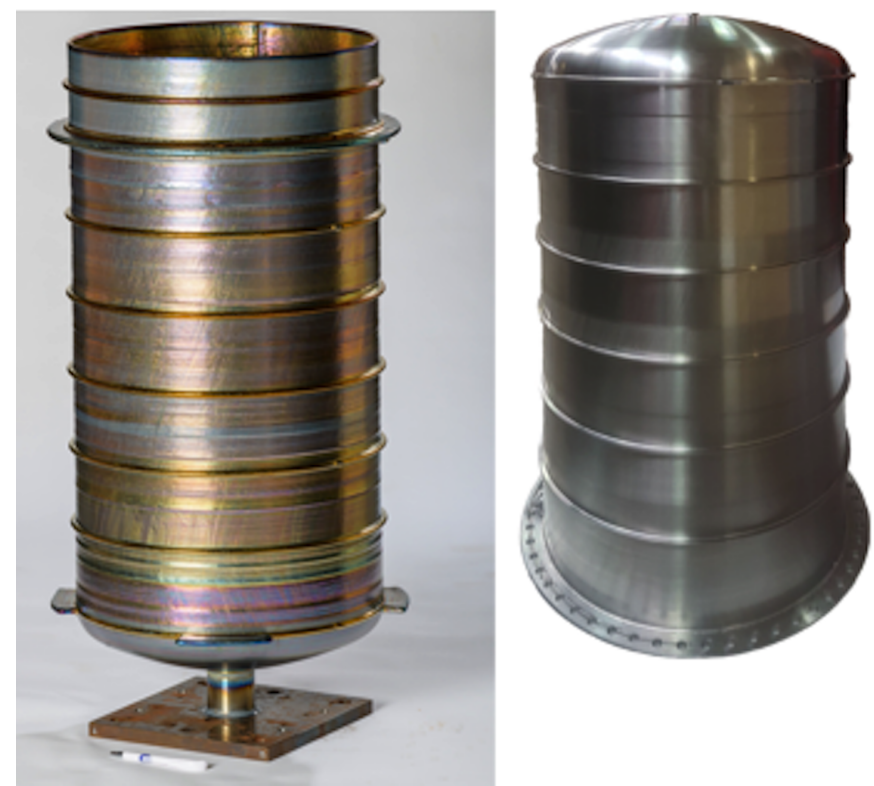

Figure 9: A Ti-6Al-4V pressure vessel prototype manufactured by the Cranfield University WAAM process: (Left) post wire + are AM processing and (Right) final machinied component (Courtesy of Filomena Martina)

\subsection{Recycling of Powder and Swarf into wire feedstock}

With the increase in wire fed additive manufacturing technologies for large components, there is an increasing need to reduce the cost of the Ti alloy wire feedstock. Work has continued at the Univ. Sheffield to develop continuous extrusion processes such as Conform ${ }^{\mathrm{TM}}$ to consolidate commercial powder [12], machined swarf and surplus AM powder into wire. Fig. 10 shows surplus/oversized AM Ti powder being converted to wire form. Such wire has good ductility and can be coiled and further cold drawn. Recently, work has been conducted with Airbus (Toulouse) to determine the effectiveness of recycling their waste Ti$6 \mathrm{Al}-4 \mathrm{~V}$ machined swarf into $10 \mathrm{~mm}$ diameter wire. 


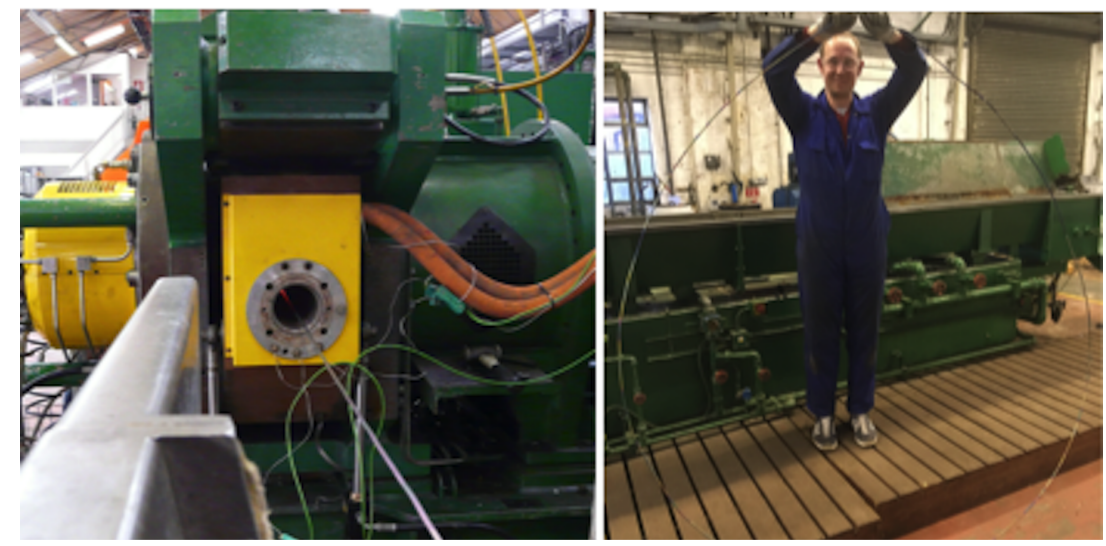

Figure 10: (Left) Titanium wire derived from surplus AM powder exiting a BWE Conform machine; (Right) Ben Thomas, Univ. of Sheffield with Ti-6Al-4V wire consolidated from powder.

\subsection{FAST-forge of near net shapes}

The Univ. Sheffield developed FAST-forge process [13] fully consolidates Ti powder and swarf into near net shapes in two solid state steps using; (1) field assisted sintering technology (FAST) followed by (2) closed die forging (see Fig. 11). Since Ti-2015, the process has picked up momentum and is now being developed through the Technology Readiness Levels in the automotive and aerospace manufacturing sectors for applications such as connecting rods and rocker arms, etc. In March 2018, the UK Secretary of State for Defence stated that "This ground-breaking method is not only faster and cheaper but could see a huge expansion of titanium parts and equipment throughout the military"[14]. The FAST process also has been demonstrated to effective enable intricate diffusion bonding (DB) of dissimilar Ti alloys prior to forging (known as FAST-DB [15]), opening the opportunity of designing components with different alloys and specific properties in subcomponent regions (Fig. 11). These developments are an example of the benefits of the EPSRC sponsored CDT in Advanced Metallics Systems, further underlining the advantages to the UK and companies for developing new technologies as well as the unique graduate training in Ti technologies.
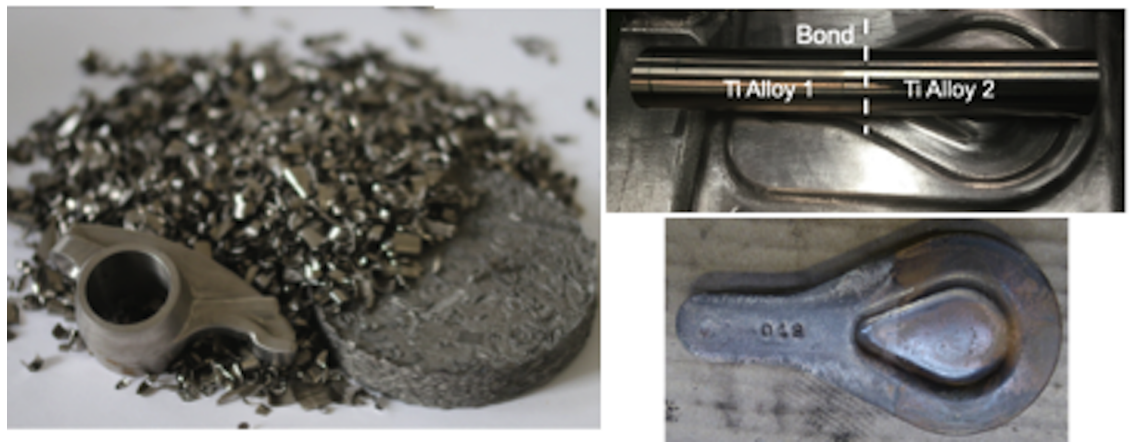

Figure 11: (Left) FAST-forge, field assisted sintering technology in combination with closed die forging is being developed to produce near net shape components, such as engine rocker arms from a range of feedstocks including machined swarf; (Right) Closed die forged I-bolt (by W.H. Tildesley, Wolverhampton, UK) from FAST preform of two dissimilar Ti alloys.

\subsection{Near net shape investment castings}

One of the most cost effective near net shaping processes, is investment casting. In the UK, AMRC Castings has now commissioned a large scale Ti casting facility centred around a 1 tonne VAR furnace with a large casting chamber, capable of pouring moulds up to $2.5 \mathrm{~m}$ diameter and $2.5 \mathrm{~m}$ height (Fig. 12). The furnace itself has the capability to pour moulds statically or centrifugally and has an active inert gas cooling system incorporated for optimisation the microstructure. This facility is supported with a variety of additive and subtractive methods for pattern manufacture direct from CAD - eliminating the need for costly 
tooling during development activities and offering the highest level of versatility. Fig. 12 also illustrates the results of collaborative work with GE Aviation (Hamble, UK) to produce a flap interface part, which is currently machined from Al alloys. An optimised final design can provide a $20 \%$ reduction in the overall weight of the assembly, by reducing the number of fasteners and parts (reduced from nine to one as cast part). Only $20 \%$ of the as cast product is machined away to produce the final part [16].
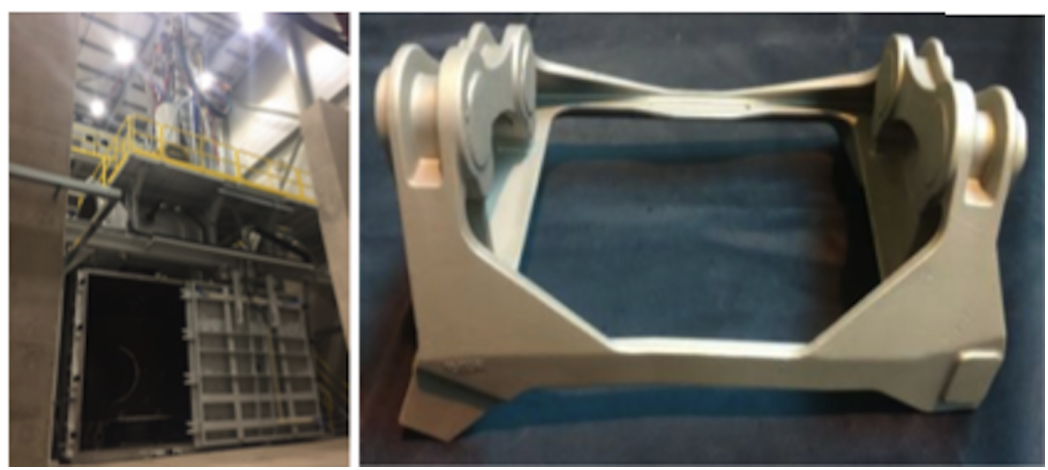

Figure 12: (Left) One tonne VAR investment casting facility at the Univ. Sheffield's AMRC Castings, Advanced Manufacturing Park, Rotherham; (Right) Flap Interface prototype investment cast Ti 6.7 kg blank [16]. (Courtesy of Matthew Cawood).

\subsection{Friction stir welding of castings}

AMRC Castings have also provided net shaped components for the UK's leading joining research institute, TWI Ltd, on a European Space Agency (ESA) sponsored project to develop a low cost method to produce Ti-6Al-4V satellite propellant tanks [17]. TWI Ltd with technical support from Airbus Sapce and Defence initially conducted a detailed study on the effect of friction stir welding (FSW) of cast Ti-6Al-4V product with rigorous mechanical testing. This has led to the manufacture of prototype tank by the friction stir welding of two hemisphere domes with a cylindrical section of approximately $42 \mathrm{~cm}$ diameter (Fig. 13). Such development has demonstrated a lower cost processing route, compared to the existing forging and forming routes.
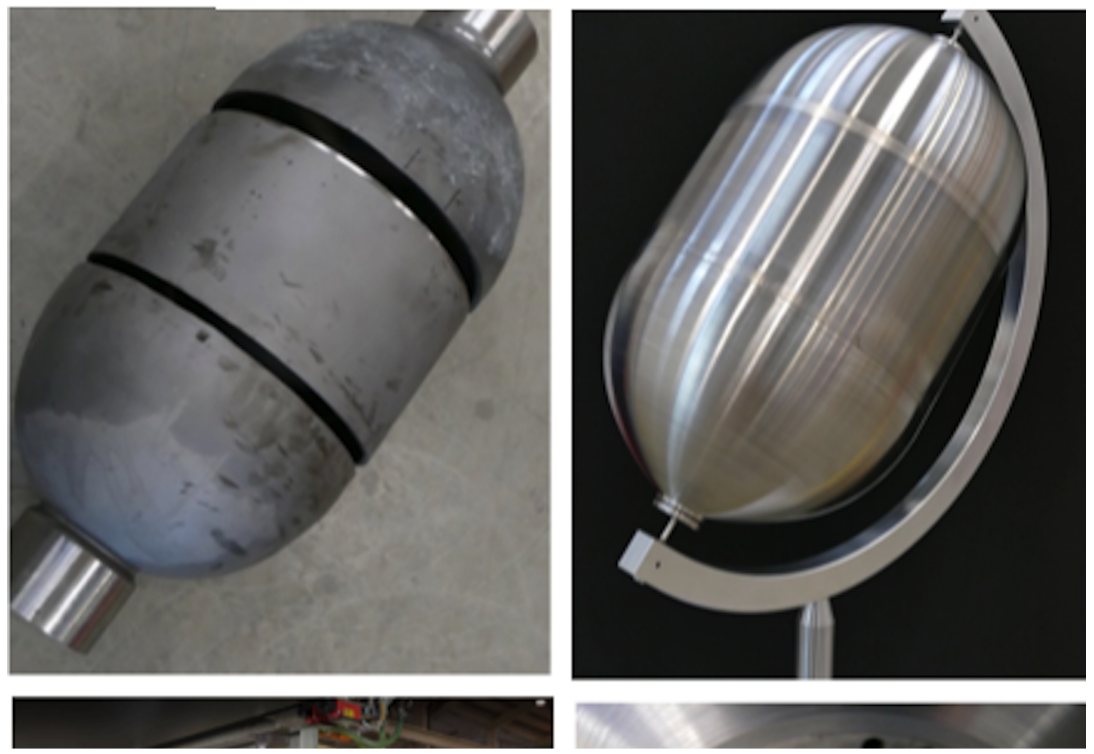
Figure 13: The prototype propellant tank manufactured using stationary shoulder FSW of two hemispherical domes with a cylindrical section; Photograph (Top left) before and (Top right) after FSW operation. The tank dimensions are approx. $75 \mathrm{~cm}$ in length by $42 \mathrm{~cm}$ diameter; (Bottom left) Photograph of the tank mounted on the welding fixture; (Bottom right) stationary shoulder FSW tool setup. The W-25Re probe rotates through a stationary shoulder mounted in a welding head. Channels for Ar flow are also visible [17]. (Courtesy of Richard Freeman)

\section{$\underline{\text { Acknowledgements }}$}

Martin Bache (Univ. Swansea), Matthew Cawood (AMRC Castings), Fionn Dunne (Imperial College London), Richard Freeman (TWI Ltd.), Russell Hodgetts (Univ. Bradford), Nicholas Jones (Univ. Cambridge), Rob Lancaster (Univ. Swansea), Filomena Martina (Univ. Cranfield), Ian Mellor (Metalysis Ltd.), João Quinta de Fonseca (Univ. Manchester).

\section{$\underline{\text { References }}$}

[1] Z. Zhang et al.Jnl. Mech. Phys. Solids. 95 (2016) 393-410.

[2] S. Joseph et al.Intl. Jnl. Plasticity, 110 (2018) 38-56.

[3] Z. Zheng et al.Intl. Jnl. Plasticity. 111 (2018) 234-252.

[4] http://www.imperial.ac.uk/hexmat/about-us/

[5] D. Lunt et al.Scripta Mater. 145 (2018) 45.

[6] R.C. Hurst et al.Theor. Appl. Fract. Mech. 86 (2016), 69-77.

[7] R.J. Lancaster et al.Mater. Sci. Eng. A 748 (2019) 21-29.

[8] D.T.S. Lewis et al.Mater. Sci. Eng. A 754 (2019) 719-727

[9] J.M. Bennett et al.Mater. Charact. 142 (2018) 523.

[10] E.L. Pang et al.Acta Mater. 153 (2018) 62.

[11] S.W. Williams et al.Mater. Sci. and Tech. 32 (2015) 641-647.

[12] B. Thomas et al.Mater. Sci. and Tech. 33 (2017) 899-903.

[13] N.S. Weston, M. Jackson. J. Mater. Process. Tech. 243 (2017) 335-346.

[14] https://www.gov.uk/government/news/porton-down-scientists-on-brink-of-titanium-revolution

[15] J.J. Pope et al.J. Mater. Process. Tech. 269 (2019) 200-207.

[16] A. Agarwal et al.The Royal Aeronautical Society's 5th Aircraft Structural Design Conf. (Oct 2016)

[17] R. Freeman et al.ASM Intl. Conf. on Adv. Mater. and Processes (ADMAT 2017). 